\title{
Strength and status of dental specialty societies in Nepal
}

Koirala PK ${ }^{1}$, Pradhan $\mathrm{S}^{2}$, Shrestha $\mathrm{R}^{3}$, Bhochhibhoya $\mathrm{A}^{4}$, Thapa $\mathrm{A}^{5}$, Karn $\mathrm{G}^{6}$, Sigdel B ${ }^{7}$

${ }^{1}$ Senior Consultant, Department of Periodontology and Oral Implantology, National Academy of Medical Sciences, Kathmandu, Nepal.

${ }^{2}$ Professor, Department of Periodontology and Oral Implantology, National Academy of Medical Sciences, Kathmandu, Nepal.

${ }^{3}$ Lecturer, Department of Periodontology and Oral Implantology, National Academy of Medical Sciences, Kathmandu, Nepal.

${ }^{4}$ Lecturer, Department of Prosthodontics, Institute of Medicine, Kathmandu, Nepal.

${ }^{5}$ Associate Professor, Department of Conservative Dentistry and Endodontics, National Academy of Medical Sciences, Kathmandu, Nepal.

${ }^{6}$ Lecturer, Department of Oral and Maxillofacial Surgery, National Academy of Medical Sciences, Kathmandu, Nepal.

${ }^{7}$ Lecturer, Department of Pediatric Dentistry, Pokhara Academy of Health Sciences, Pokhara, Nepal.

\section{Abstract}

Introduction: It's been over a decade since different dental speciality societies have been established in Nepal. These specialities have generated important human resource, which have contributed to uplift dental care syatem in Nepal. The study was designed with the objective of assessing strength and status of dental specialities in Nepal.

Materials and Methods: The cross-sectional observational study was conducted from October 2020 to December 2020. Nepal Medical Council (NMC) websites, dental specialities websites as well as personal communication with responsible persons of the dental societies were assessed to collect data. Demographic and professional details, specialist number, age, gender, work place, place of graduation and graduation year were entered into Microsoft Excel Sheet. Data was analyzed based upon frequency distribution and percentage.

Result: According to NMC record, total number of dental specialists in dentistry is 616, till December 2020. Out of them, 451 specialists were registered with the dental societies, who were included in this study. There were 6 speciality dental societies in Nepal and most of the societies were a decade old and had more than 50 members. Orthodontics association was the oldest with 164 members. The highest number of specialists were in the age group 30-40 year in all the dental specialties and they were mostly working in Kathmandu valley.

Conclusion: Different dental speciality societies have been growing throughout the country which have produced qualified manpower for providing specialized dental services. These societies are contributing towards achieving goals of better oral health care delivery in the nation.

Key words: Dentistry; Nepal; Post graduate; Society; Speciality.

\section{Conflict of Interest: No}

\section{*Corresponding Author}

Dr. Rejina Shrestha, Lecturer

Department of Periodontology and Oral Implantology, National Academy of Medical Sciences, Kathmandu, Nepal.

E-mail: rejinashrestha811@gmail.com

\section{Introduction}

$\mathrm{T}$ The field of dentistry has taken shape in Nepal with the increase in the number of dental colleges, since the beginning of the new millennium. Its almost 8 decades since qualified dentists started dental practice in Nepal and these pioneers have served the people with their hard work, dedication and knowledge. ${ }^{1}$ Post 
graduate studies in different dental specialties have been running for a decade. According to the dental post graduate regulation 2017 published by NMC, the award of postgraduate dental degrees includes Master of Dental Surgery (MDS) in the related specialty of dental sciences. The award of the degree by different Universities/Institutions/Academy throughout the country is same. Specialists in significant numbers are providing services throughout the country. Different universities and institutions have started different specialities programs and they are conducting various scientific researches and academic activities. Different specialty societies are gaining national as well as global recognition and they represent the interests of their speciality and offer advice to the providers of specialist services.

The aim of specialist societies is to promote continuing professional education at local and regional level, organize national and international meetings and events to promote continuing professional development, advise on the best evidence required to enable the individual to demonstrate their continuing fitness to practice, guide on standards of practice within the scope of their specialist area, agree specialty specific outcome measures against which the performance of both individual dentists and unit groups can be assessed, promote the development of evidence based practice, and develop clinical guidelines for good practice. $^{2}$

Specialists in significant numbers are providing services throughout the country.,4 Along with the education and growing knowledge and experiences, people are getting quality services. This study aimed to provide a detailed description of different specialty societies and their members in Nepal.

\section{Materials and Methods:}

A cross-sectional observational study was conducted from October 2020 to December
2020. Data were collected through resources made available in council websites, dental specialities websites and personal communication with responsible persons of the societies and associations. The data included number of societies and age, gender, work place, graduation year and graduating place of the members. Age was distributed in 5 groups: 21-30, 31-40, 41-50, 51-60 and above 60 years. Work place was distributed as within Kathmandu valley and outside the valley. Graduating place was categorized as within and outside Nepal. Graduation year was grouped as before 2000, 2000-2010 and 2011-2020. The data was entered into Microsoft Excel Sheet and analyses was done using frequency distribution and percentage.

\section{Results}

The outcome of the study revealed that there were 6 specialty dental societies, which included Nepalese Society of Periodontology and Oral Implantology (NSPOI), Nepalese Prosthodontic Society (NPS), Orthodontic and Dentofacial Orthopedic Association of Nepal (ODOAN), Nepalese Association of Oral and Maxillofacial Surgery (NAOMS), Conservative Dentistry and Endodontic Association of Nepal (CDEAN) and Nepalese Association of Pediatric Dentistry (NAPD). These are non-profit organizations and the details of these societies are tabulated in table 1 . There were a total number of 451 dental specialists registered with the dental societies. Among them, 254 were male and 197 were female. The society with the largest number of specialists was ODOAN, with 164 members. Male specialists were predominant in ODOAN, NPS and NAOMS, whereas in NSPOI, CDEAN and NAPD had higher female members as shown in Graph 1.

Graph 2 shows the distribution of the specialities according to these group. The highest number of specialists were in the age group 31-40 year in all the specialties. Graph 3 shows the 
current working place of the specialists. Many specialists were found to be working in and around the valley in all the societies. Graph 4 shows the distribution of the specialties according to graduating place. Specialists graduating from outside the country were seen to be higher in ODOAN and NAPD. Graph 5 shows the graduating year of the specialists, which showed a sharp upsurge in the number of graduating specialists in the last decade.

Table 1: Establishment, membership and publications of specialty societies.

\begin{tabular}{|l|c|c|c|c|c|c|}
\hline Societies & NSPOI & NPS & ODAN & NAOMS & CDEAN & NAPD \\
\hline Establishment & 2014 & 2012 & 2007 & 2011 & 2015 & 2016 \\
\hline Founders & 13 & 9 & 5 & 7 & 10 & 9 \\
\hline Membership & 56 & 67 & 164 & 70 & 52 & 24 \\
\hline
\end{tabular}

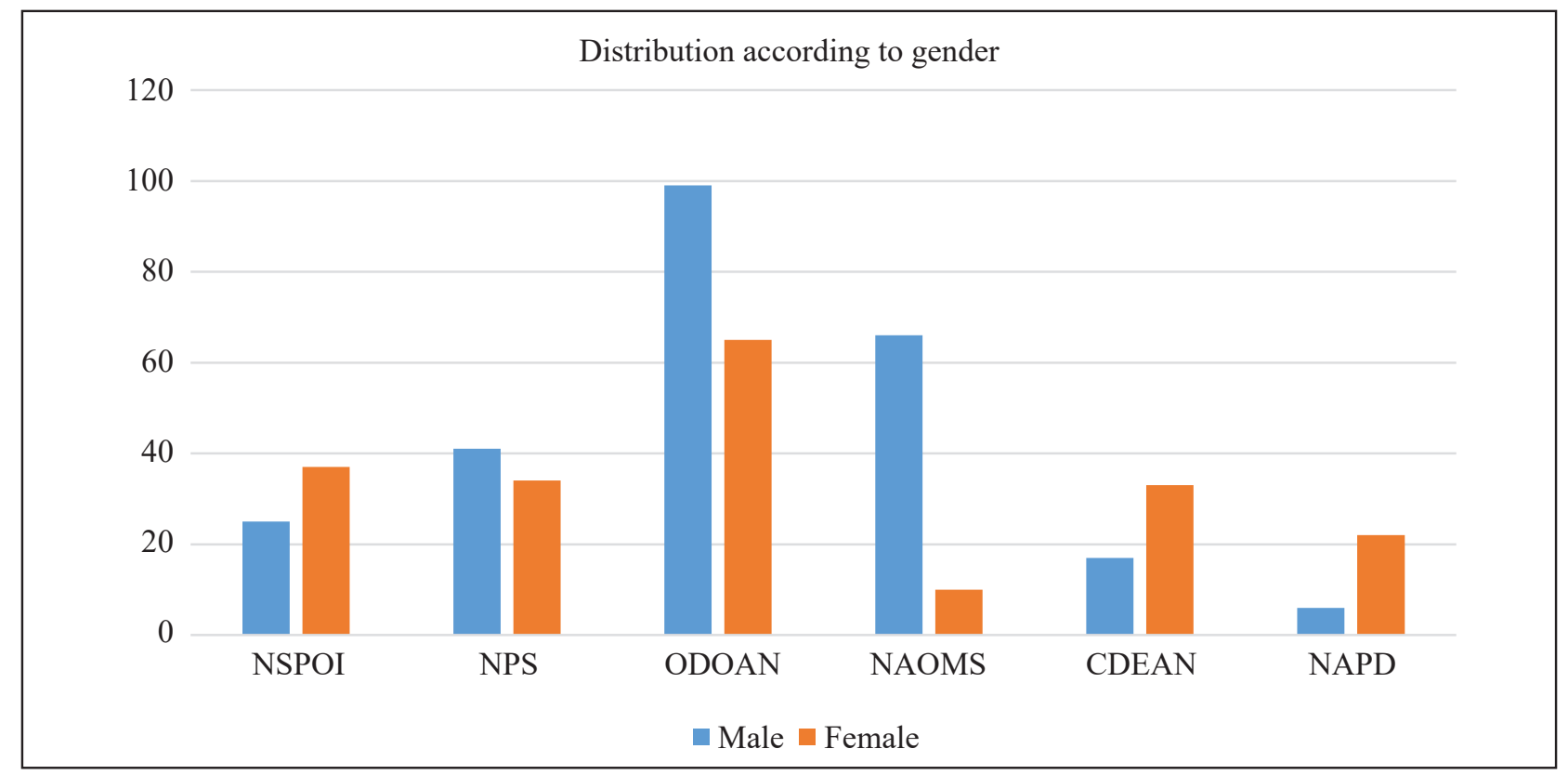

Graph1: Distribution according to gender

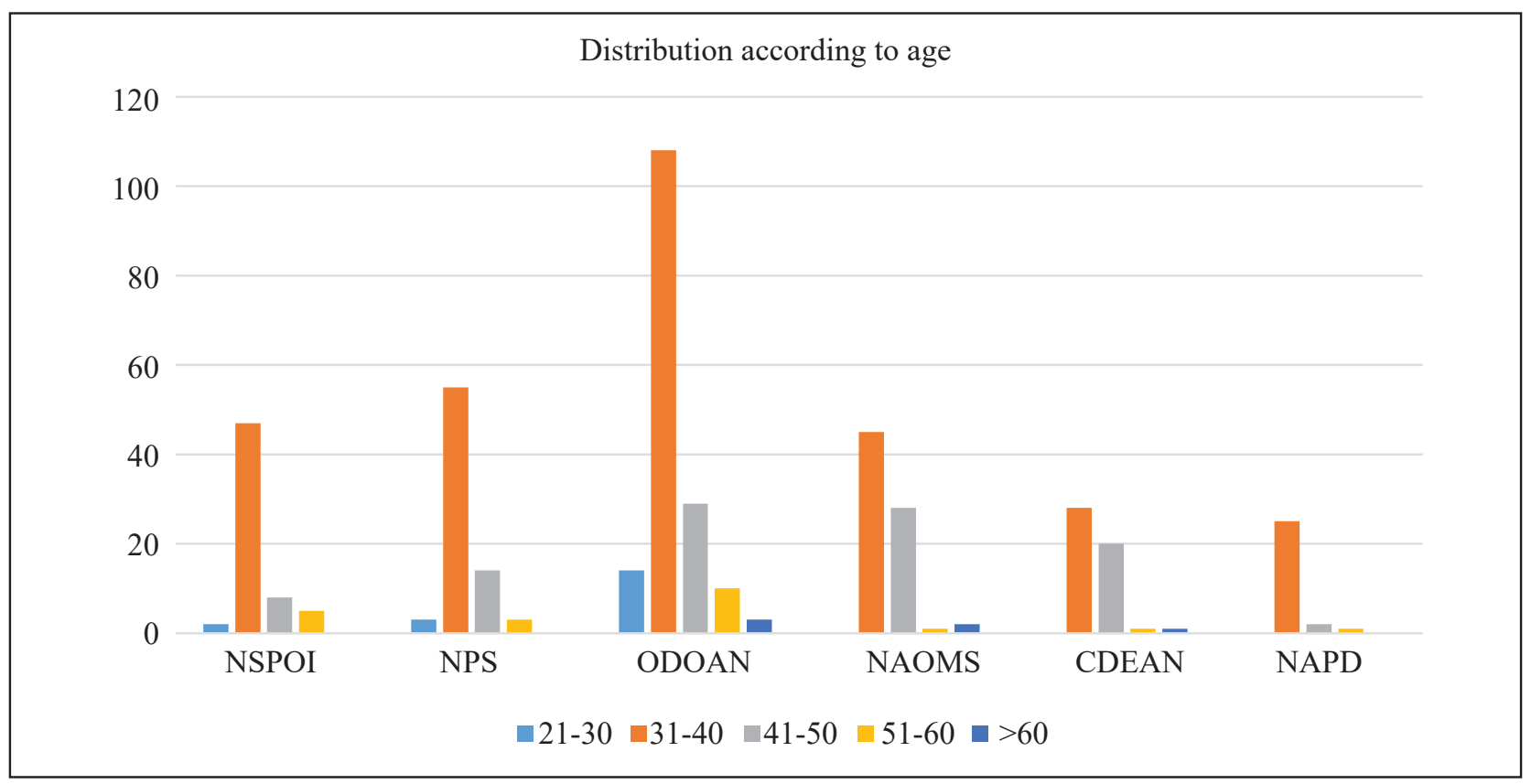

Graph 2: Distribution according to age 


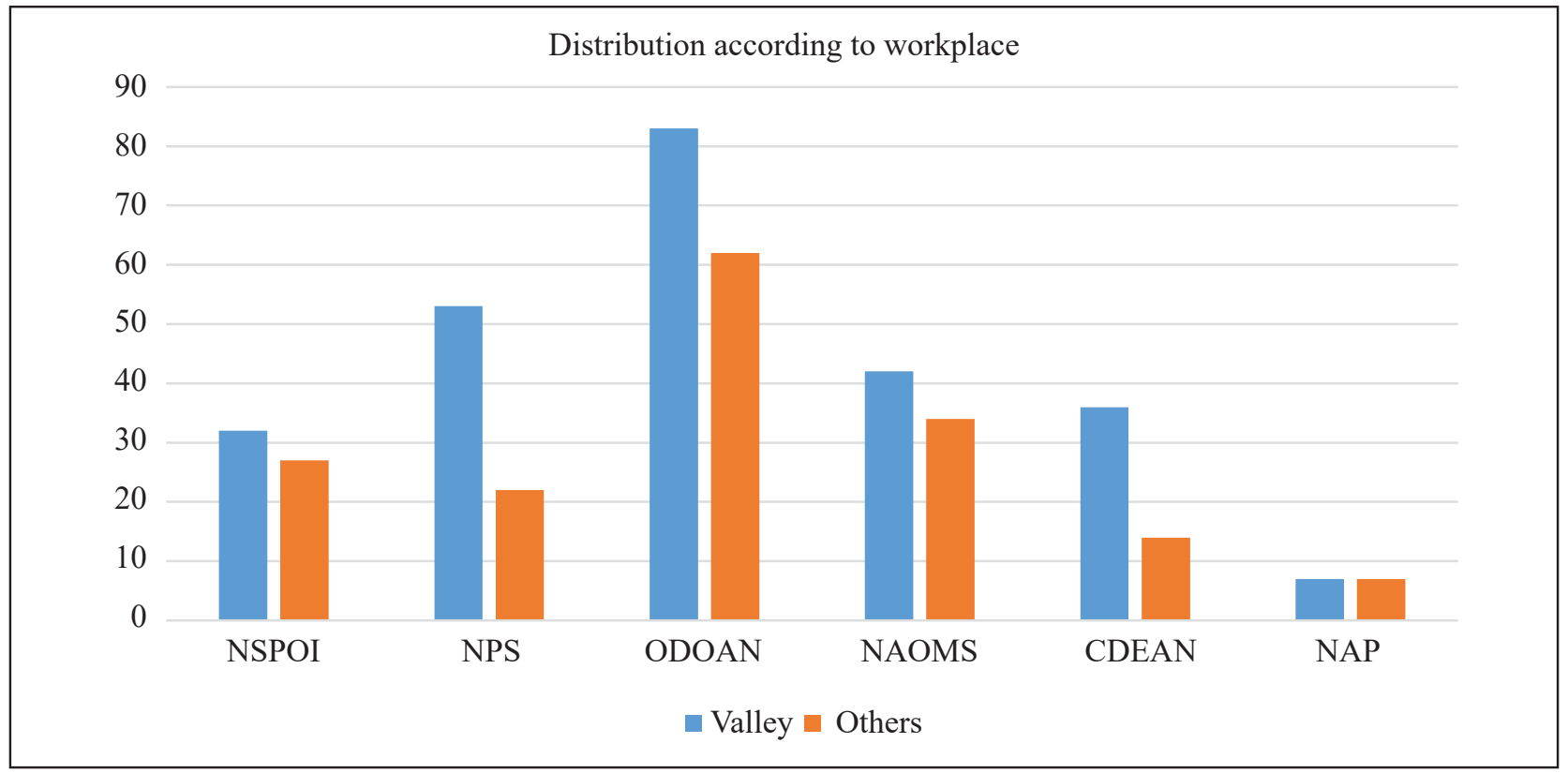

Graph 3: Distribution according to workplace

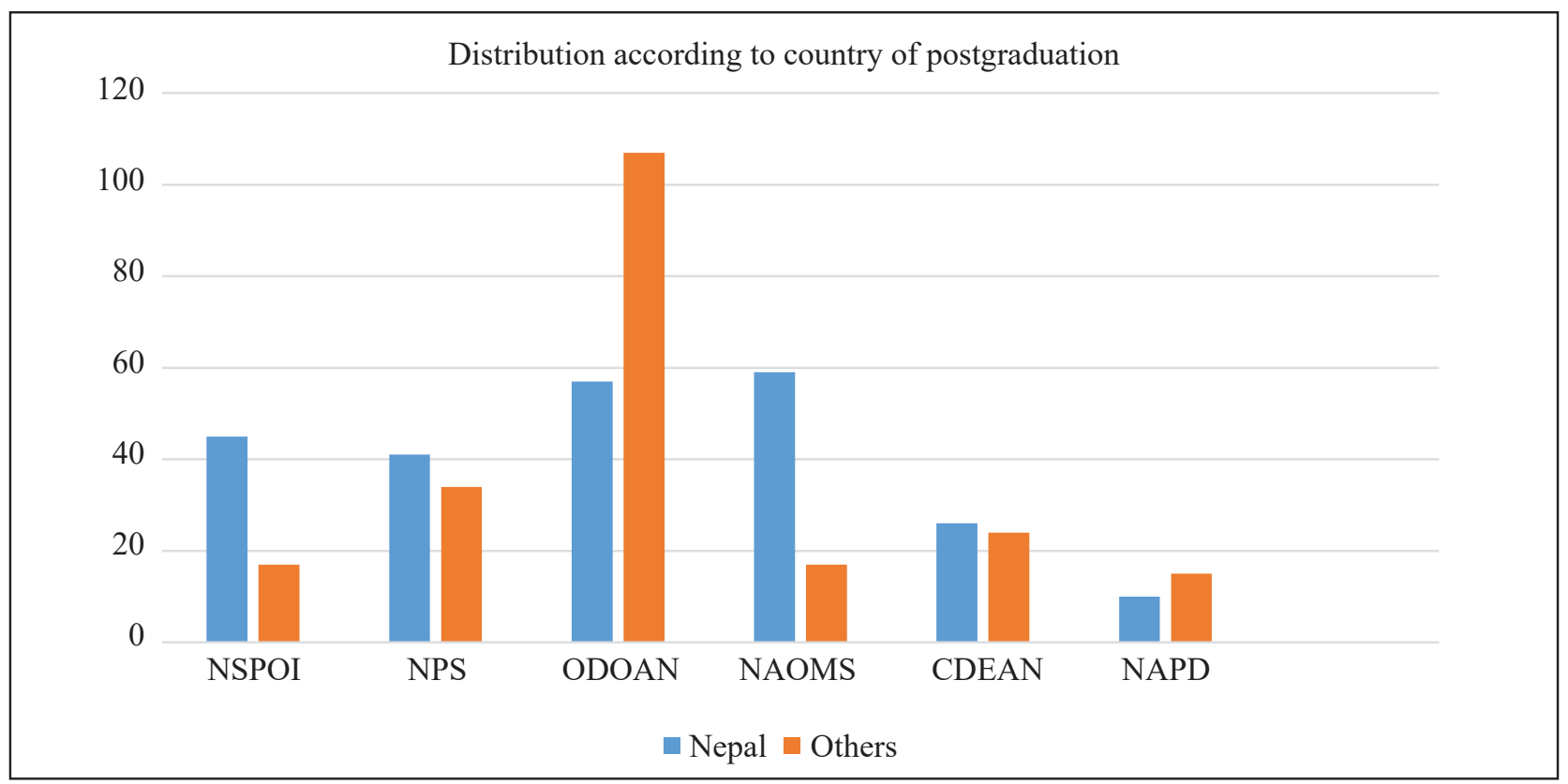

Graph 4: Distribution according to country of postgraduation

\section{Discussion}

Oral and dental diseases are among the most prevalent diseases of humankind, periodontitis being the sixth most prevalent disease worldwide which affects nearly 800 million individuals. ${ }^{5}$ If untreated dental diseases lead to tooth loss which causes masticatory, phonetic, aesthetic and social impairment. ${ }^{6-7}$ Dental caries and periodontal problem are the most prevalent dental diseases in Nepal. ${ }^{8}$ Due to lower socioeconomic status of the Nepalese population, regular oral health care has received less priority. Though oral health care workers, hospitals and clinics are increasing in the major cities, majority of people in rural area are away from qualified personnel and standard treatment. The present study provides information on different dental speciality societies and the members 


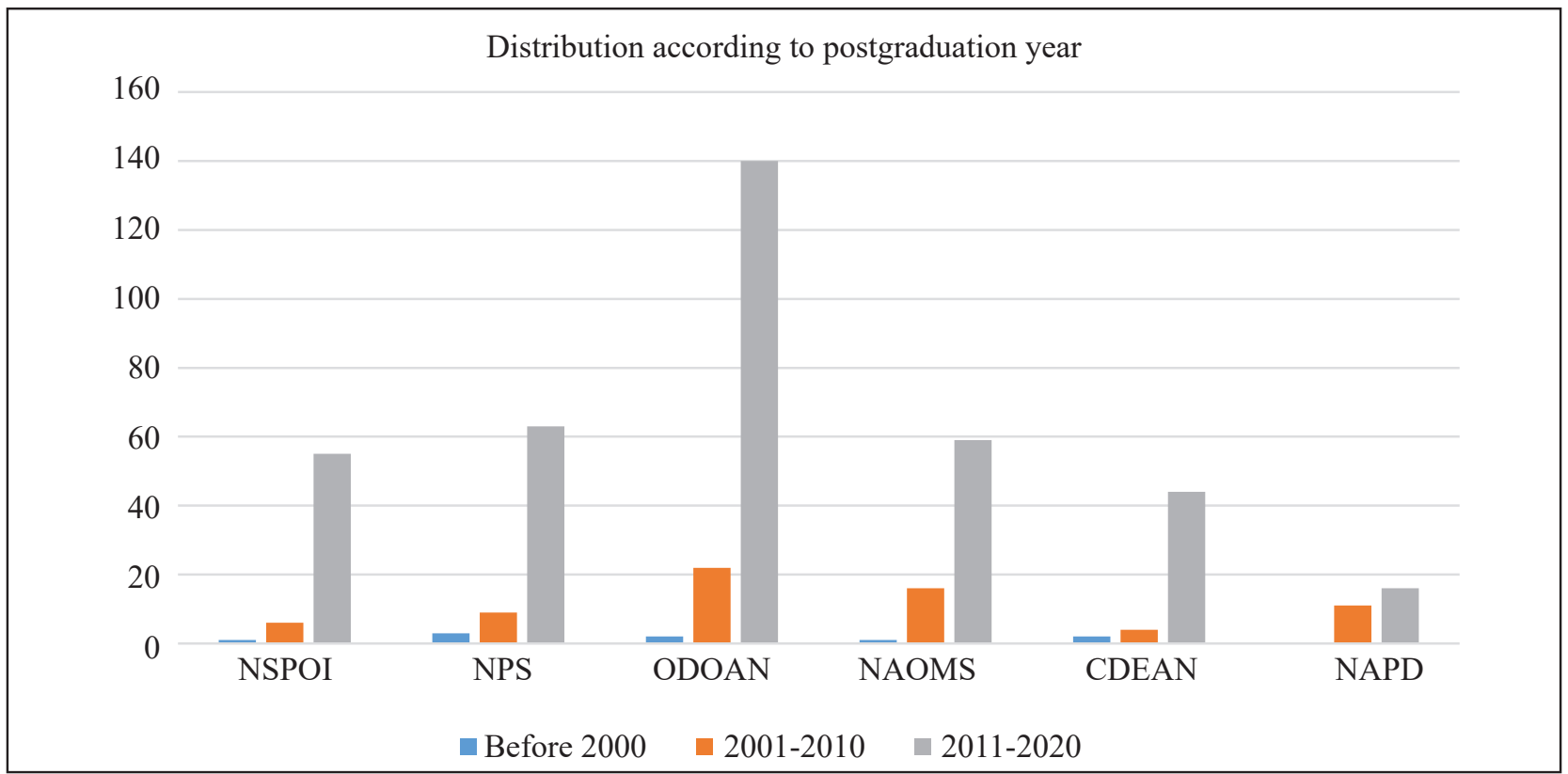

Graph 5: Distribution according to postgraduation year

working under them. ODAN is the first dental specialty society to be established in Nepal and has the highest number of specialists. According to gender, the male to female ratio of the specialities was found to be 1:0.79. There were highest number of dental specialists in the age group 31-40 year. There were 20 specialists under the age of 30 and 6 specialists over the age of 60 .

It was only in the year 2008 that the post graduate education commenced in Nepal. So, in the earlier days most of the dental surgeons graduated from the neighboring countries like India, China, Russia, Pakistan and Bangladesh. With the start of post graduate dental education in the country, the access has increased for Nepali candidates seeking post graduate education which has also reduced the expenses for education. The first postgraduate dental course established in Nepal was Orthodontics and Dentofacial Orthopedics. The number of orthodontists is highest among different dental specialities in Nepal and has remarkably increased after the year $2010 .^{9}$

The other postgraduate courses available in Nepal are Periodontology and Oral Implantology, Prosthodontics and Maxillofacial Prosthetics,
Conservative Dentistry and Endodontics, Oral and Maxillofacial Surgery, Pedodontics, Oral Medicine and Radiology, Oral Pathology and Community Dentistry. Besides these nine specialities, three other specialities recognized by American Dental Association (ADA) are Dental anesthesiology, Oral and Maxillofacial Radiology and Orofacial pain, ${ }^{10}$ which are not available in Nepal. After the introduction of the postgraduate courses through Tribhuvan University, Kathmandu University, National Academy of Medical Sciences and B.P. Koirala Institute of Health Sciences, there has been an upsurge in the number of dental specialities in the last decade.

Dental specialties protect the public, nurture the art and science of dentistry, and improve the quality of care. The need of the public is best served by general dental practitioners and specialist are essential to maintain and restore oral health, advance knowledge and skill. Areas of interest could be developed and advanced through education, practice and research. With the growth and development of different specialties in the country, there is rise in standard of dental care facilities 


\section{Conclusion}

Different dental speciality societies are growing throughout the country which has produced qualified manpower providing specialized services in Nepal. The establishment of these societies has positive impact on the dental education, continuing medical/dental education, post graduate studies, professional courses as well as research activities. We can anticipate that quality of care to the patients will definitely improve in days to come with increasing number of specialists.

\section{Acknowledgement:}

My sincere acknowledgement to Dr Ranjita Shrestha Gorkhali, Dr Manish Bajracharya, Dr Ranjan Thapaliya, Dr Asal Koirala for helping me conduct this research.

\section{References}

1. Shrestha RM. Thirty glorious years of Nepal dental association. J Nepal Dent Assoc. 2020;20(31):60-2.

2. Coulthard P, Horner K, Sloan P, Theaker ED. Master Dentistry E-Book: Volume 1: Oral and Maxillofacial Surgery, Radiology, Pathology and Oral Medicine: Elsevier Health Sciences; 2013.

3. Maharjan SK, Mathema S. Survey on Status of Prosthodontists in Nepal, Service Rendered and
Their Level of Satisfaction. J Nep Prosthodont Soc 2018;1(1):26-32.

4. Birajee G, Koirala B, Limbu S, Dali M, Shrestha S. History of Pediatric Dentistry in Nepal. J Nepal Assoc Pediatr Dent. 2020;1(1):27-31

5. Kassebaum N, Smith A, Bernabé E, Fleming T, Reynolds A, Vos T, et al. Global, regional, and national prevalence, incidence, and disabilityadjusted life years for oral conditions for 195 countries, 1990-2015: a systematic analysis for the global burden of diseases, injuries, and risk factors. J Dent Res. 2017;96(4):380-7.

6. Tonetti MS, Jepsen S, Jin L, Otomo-Corgel J. Impact of the global burden of periodontal diseases on health, nutrition and wellbeing of mankind: A call for global action. J Clin Periodontol. 2017;44(5):456-62.

7. Righolt A, Jevdjevic M, Marcenes W, Listl S. Global-, regional-, and country-level economic impacts of dental diseases in 2015. J Dent Res. 2018;97(5):501-7.

8. Pradhan S, Koirala PK Periodontics in Nepal: Where Have We Reached? J Nep Soc Periodontol Oral Implantol 2019;3(1):38-9.

9. Shrestha RM, Bajracharya M, Yadav R, Gupta A. Orthodontists of Nepal: The demographic and professional characteristics. JODAN 2020;10(3):3-9.

10. Fields HW, Casamassimo P, Owsiany DJ, Saperstein MJJode. The case for tying specialty status to completion of dental residency: Dental education's stake. 2020;84(8):852-6. 